\title{
Chronic Respiratory Diseases and Neurodegenerative Disorders: A Primer for the Practicing Clinician
}

\author{
Lorenzo Falsetti $^{a} \quad$ Giovanna Viticchi $^{b}$ Vincenzo Zaccone ${ }^{a} \quad$ Nicola Tarquinio $^{c}$ \\ Lorenzo Nobili $^{a}$ Cinzia Nitti ${ }^{a}$ Aldo Salvi ${ }^{a}$ Gianluca Moroncini ${ }^{d}$ \\ Mauro Silvestrini ${ }^{b}$ \\ anternal and Subintensive Medicine Department, Azienda Ospedaliero-Universitaria "Ospedali Riuniti," Ancona,

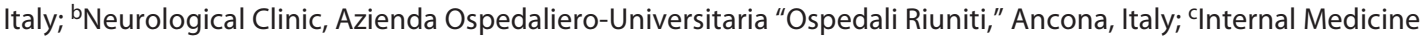

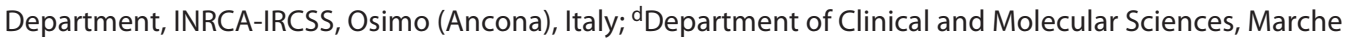 \\ Polytechnic University, Ancona, Italy
}

\section{Highlights of the Study}

- Neurodegenerative and respiratory diseases are strongly connected by ageing and shared risk factors.

- Alzheimer's disease is related to chronic obstructive lung disease due to smoking, hypoxaemia, and atherosclerosis.

- Neurodegenerative disorders are often associated with an increased prevalence of sleep-disordered breathing.

- Parkinson and parkinsonisms are more often associated with chronic restrictive respiratory insufficiency.

\section{Keywords}

Alzheimer's disease · Parkinson's disease · Neurologic diseases · Respiratory diseases

\footnotetext{
Abstract

Chronic respiratory disorders represent a world epidemic. Their incidence and prevalence in the world population is increasing, and especially among elderly subjects, they are commonly associated with other pathologies, often generating a status of high clinical complexity. Neurology, internal medicine, and pneumology specialists should be aware
}

of the common background of these disorders in order to treat correctly the patient's comorbid state and optimize the treatment considering potential overlaps. In this review, we aimed to focus on the relationships between chronic respiratory disorders and chronic neurodegenerative diseases at different levels; we review the shared risk factors and the interactions between disorders, the indications to explore respiratory function in neurodegenerative diseases, pathology-pathology and drug-pathology interactions in patients affected by both chronic neurologic and respiratory diseases.

(c) 2021 The Author(s).

Published by S. Karger AG, Basel
C 2021 The Author(s).

Published by S. Karger AG, Basel

This is an Open Access article licensed under the Creative Commons Attribution-NonCommercial-4.0 International License (CC BY-NC) (http://www.karger.com/Services/OpenAccessLicense), applicable to the online version of the article only. Usage and distribution for commercial purposes requires written permission. 


\section{Introduction}

Both chronic respiratory and neurodegenerative disorders are increasing worldwide, along with the other non-communicable diseases, mainly because of ageing of the population [1]. These diseases are both associated with a decreased quality and a reduced expectancy of life. The main link between these conditions is ageing itself; however, other shared risk factors could increase the strength of this association. In this narrative review, we aimed to identify the shared risk factors, the pathologypathology and drug-pathology interactions between neurodegenerative disorders and chronic respiratory diseases.

\section{Research Strategy}

We searched PubMed/MEDLINE for case reports, reviews, and original research articles in the time frame from January 1, 2000 to February 1, 2020. We used MeSH major terms and considered: "Pulmonary Disease, Chronic Obstructive" [MeSH] or "Lung Diseases, Interstitial" $[\mathrm{MeSH}]$ or "Asthma," [MeSH] or "Lung Neoplasms" $[\mathrm{MeSH}]$ in combination with "Tauopathies" $[\mathrm{MeSH}]$ or "Alzheimer Disease" $[\mathrm{MeSH}]$ or "Parkinson Disease" [MeSH] or "Multiple System Atrophy" [MeSH] or "Supranuclear Palsy, Progressive," [MeSH] or "Corticobasal Degeneration" [MeSH]. The group of reviewers favoured the inclusion of articles from the past 5 years, although they did not exclude highly cited older reports; the reference lists of articles identified by this search strategy was also reviewed, and the working group selected those references judged to be relevant.

\section{Shared Risk Factors and Interactions between}

Respiratory Diseases and AD

Cigarette smoking has been associated with cognitive deterioration and represents a risk factor for Alzheimer's disease (AD) [2]. The risk of developing $\mathrm{AD}$ increases proportionally with the time of exposure and it has been hypothesized a role of APOE genotype in the association between cigarette smoking and risk of $\mathrm{AD}[3]$ : all the evaluated studies report an increased risk for $\mathrm{AD}$ in active smokers, with a dose-dependent effect, and to a lesser extent in ex-smokers [4-6]; in the population of smokers, the highest risk has been observed among carriers of the APOE $\varepsilon 4$ allele [7]. The typical neuroanatomic alterations observed among smokers are characterized by a reduction of hippocampal volume, while cognitive impairment is mainly due to a memory and learning deficit [8-10]. Smoking is associated with cognitive deterioration with several other shared physiopathogenetic mechanisms: for example, chronic cerebrovascular pathology, affecting both large and small vessels and COPD in the subset of chronic hypoxaemic subjects, is associated with cognitive deterioration [11].

The relationship between COPD, hypoxaemia, and cognitive deterioration has been extensively evaluated in different clinical settings; a cognitive deterioration without definite neurodegenerative pathology is present in COPD subjects with a prevalence ranging between $10.4 \%$ and $48.5 \%$ [12-14]. This association however has been confirmed only in patients with more severe COPD forms after covariate adjustment [15]. Moreover, among COPD patients, some pre-clinical neurodegenerative pathologies, such as non-amnestic mild cognitive impairment are more represented than in general population [16]. A chronic obstruction of lung function in younger ages, as in COPD or in asthma, has been associated with a higher risk of mild cognitive impairment or dementia in the geriatric age [17].

$\mathrm{AD}$ is also associated with a higher prevalence of sleepdisordered breathing (SDB), particularly OSAS [18, 19]. The association between $\mathrm{AD}$ and OSAS is secondary to both central and peripheral alterations and associated with a greater cognitive deterioration in respect to $\mathrm{AD}$ alone $[20,21]$. In the last years, several authors found that OSAS could be considered a risk factor for progression of cognitive impairment $[22,23]$.

Moreover, in this subgroup of patients, the cognitive deterioration could be slowed by CPAP treatment [24]. Cancer incidence [25], particularly lung cancer [26], seems to be lower in $\mathrm{AD}$ and in other central neurodegenerative diseases. Several observations from animal models, transcriptomic meta-analyses, and matrix factorization studies underline the existence of molecular substrates supporting the hypothesis of an inverse comorbidity relationship between AD and lung cancer [27-29].

\section{Shared Risk Factors and Interactions between}

\section{Respiratory Diseases and PD}

The role of cigarette smoking in Parkinson's disease (PD) has been extensively studied. Recent meta-analyses underlined a reduced risk of developing PD in previous smokers, which is further reduced in active smokers at the time of the study [30,31]. The biological rationale of this association is not known, but it is attributed to the effect of nicotine in stimulating dopamine release and modulating the central monoamino-oxydase activity. However, several authors postulated that, despite the high number of articles suggesting this hypothesis, this observation 
could be caused by some methodological biases, suggesting that the observed neuroprotective effect of smoking could be associated with reverse causality [32]. Moreover, some retrospective studies underlined a higher risk of $\mathrm{PD}$ among COPD patients [33].

Aspiration pneumonia represents the $70 \%$ of $\mathrm{PD}$-associated deaths [34]. This pathology should be always suspected in PD patients developing fever or respiratory symptoms, particularly in those with known dysphagia or sialorrhoea; a normal deglutition requires an appropriate pharyngeal and laryngeal stimulation, an adequate muscular tone, and proper coordination between deglutition and action of respiratory muscles. If the bolus is accidentally sent in the airways, cough acts as a protective mechanism. With disease progression, mastication and deglutition are difficult due to bradykinesia, stiffness, and dyskinesias. A sensitive deficit in the glossopharyngeal and vagus nerve territories can contribute to dysphagia [35]. Disturbances in deglutition that increase oral material and accidental aspiration are present in $60 \%$ of $\mathrm{PD}$-affected patients. This is important, as aspiration of saliva itself can be a cause of pneumonia, with no relationship with meals. The coordination of breathing with deglutition is dysfunctional in these subjects, and cough becomes less effective for increased chest wall stiffness and a reduction of the sensorial component of cough reflex. The PD medical treatment can improve respiratory function, but levodopa does not seem to improve dysphagia. Sialorrhoea can be treated with anticholinergic drugs, as clonidine, or with surgical resection of salivary glands, radiotherapy, or local treatment with botulinic toxin. Tracheostomy can be suggested as the last preventive measure, to be considered only after an extensive evaluation of the patient and his quality of life. Oropharyngeal dysphagia affects 4 out of 5 PD patients, and it is an often underestimated complication by both patients and caregivers [36]. This symptom, characterized by the chronic aspiration of oral or gastric material due to alterations of deglutition mechanisms, can cause anatomic alterations that can manifest with nodular, multilobular, or centrilobular alterations, "tree-in-bud" and interstitial thickening which can evolve to lung fibrosis [37]. The most common histopathological finding in chronic aspirative pneumonia is compatible with bronchiolitis obliterans-organizing pneumonia, often combined with suppurative granulomas, bronchiolitis, and bronco-pneumopathy associated with suppurative granulomas [38].

The prevalence of restrictive diseases in patients affected by PD varies between $28 \%$ and $85 \%$ [36], with extreme variability caused by antiparkinsonian drug use.
Dyspnoea associated with restrictive diseases usually starts as an exertional dyspnoea which progressively evolves into a resting dyspnoea associated with a worsening of typical PD motor symptoms, such as falls or gait freezing [39]. The pathophysiological mechanisms underlying this are not well understood. The pathophysiological mechanisms of restrictive breathing disorders have still not been completely elucidated, albeit mainly associated with stiffness and bradykinesias of respiratory muscles and to reduced compliance of the thoracic wall. Spirometry is compatible with muscle weakness of thoracic wall muscle weakness which is similar to peripheral neuromuscular disease, but there is little evidence of this effect in PD [40]. Osteomuscular alterations of the neck, as camptocormia, can contribute to restrictive pattern, thus limiting thorax expansion and reducing respiratory volumes [41-43]. A restrictive respiratory insufficiency in the setting of PD usually improves with dopaminergic treatment, which could be less effective in the most advanced stages of disease [42]. In the subset of patients in whom camptocormia is present, respiratory exercises can be effective, but this indication comes from a single case report [44]. A vigorous program of respiratory rehabilitation seems to be able to improve both respiratory and cardiovascular function $[45,46]$.

In the last decade, several authors underlined a very high prevalence (43-66\%) of SDB in PD [47-50]. Several studies suggested that a central component, associated with neurodegeneration, and a peripheral component, associated with upper respiratory muscles atonia, can be at the origin of $\mathrm{SDB}$ in PD [51]. In PD, OSAS is not necessarily related to obesity and can be associated with an increased diurnal sleepiness $[52,53]$. Several studies and meta-analyses underlined that, excluding malignant melanoma; other forms of cancer are usually under-represented in PD, especially lung or smoke-related tumours [54-56].

\section{Shared Risk Factors and Interactions between Respiratory Diseases and PSP}

There are no studies evaluating the association between progressive supranuclear palsy and COPD, lung cancer or interstitial lung disease, and further research is required in this direction. However, early dysphagia and pneumonia have been associated with increased mortality [57].

\section{Shared Risk Factors and Interactions between}

Respiratory Diseases and Parkinsonisms (MSA, CBD)

There are no studies evaluating the association between multisystem atrophy (MSA) or corticobasal degen- 
eration and COPD, lung cancer, or interstitial lung disease. Parkinsonisms however can often show several forms of dystonia involving the upper airways (vocal cords and larynx) or diaphragm motility [58]. This aspect, when associated with the common reduction of cough reflex and oropharyngeal dyssynergy, represents a risk factor for several types of respiratory comorbidities, from aspiration pneumonia to acute respiratory insufficiency. MSA is associated with a greater incidence of SDB, particularly OSAS and stridor. Daytime or nocturnal stridor is present up to $50 \%$ of the patients, and is more frequent in the advanced stages of the disease [59]. OSAS can affect $40 \%$ of MSA patients and can be associated with stridor [60]. The pathophysiological mechanism of stridor can be attributed to the dystonic contraction of the adductor muscles of larynx during inspiration, which can lead to an active constriction of larynx [61]. This nonmotor manifestation is associated with reduced survival and with an increased risk of sudden death in AMS [62] but can be treated with nocturnal CPAP or invasive ventilation $[63,64]$.

\section{Exploring Respiratory Function and Structure in AD}

Spirometric alterations in the midlife were associated with a greater risk of $\mathrm{AD}$ [65] but also with an increase in white matter lesions and lacunar infarcts, which are associated with vascular dementia [66]. Ventilatory alterations later in the life, evaluated with spirometric indices (PEF-R, FEV1, MEF50\% FVC, and MEF25\% FVC), have been associated with a greater risk of dementia independently from other known risk factors for $\mathrm{AD}$ [67]. A reduced lung function and the presence of a restrictive pattern in younger ages have been associated with a greater risk of dementia in advanced age [67].

\section{Exploring Respiratory Function and Structure in PD and Parkinsonisms}

Respiratory involvement in PD or parkinsonisms can be categorized as upper airways obstruction, restrictive pattern, complications secondary to drug withdrawal or use, and aspiration pneumonia. The difference between $\mathrm{PD}$ and parkinsonisms in term of respiratory function involvement is slight but significant. MSA, PSP, and PD share the same low central response to hypoxia, a high risk of aspiration pneumonia, and a high prevalence of SDB. PD however has a broader respiratory involvement comprising also restrictive pathology, SDB, diaphragmatic dyskinesias, and aspiration pneumonia. Upper airways obstruction is common in all the 3 forms, but it is more marked in PD due to multiple mechanisms of dis- ease, while the upper airways in MSA and PSP are often obstructed by mechanisms of laryngeal stridor.

\section{Effect of Drugs Adopted in Neurodegenerative}

\section{Diseases in Respiratory Function in $A D$}

Donepezil, galantamine, and rivastigmine are commonly used for the treatment of $\mathrm{AD}$ and act as cholinesterase inhibitors. Thus, their use, albeit not contraindicated, can be associated with exacerbation of COPD and must be strictly controlled [68], while bronchial asthma represents an absolute contraindication to their use. The use of these drugs is associated with nausea and vomiting in a percentage between 5 and $31 \%$ in various trials. There is only 1 case report which correlates this effect to aspiration pneumonia [69]. Donepezil however seems to have an effect in reducing the entity of SDB [70].

\section{Effect of Drugs Adopted in Neurodegenerative}

Diseases in Respiratory Function in PD and

\section{Parkinsonism}

Long-term complications of levodopa treatment include involuntary movements typically involving head, trunk, and limbs. A "respiratory dyskinesis" can represent the manifestation of a motor complication related to levodopa. Choreic, stereotyped and dystonic movements are present in the long-term treatment with levodopa and can interfere with a regular respiratory pattern generating dyspnoea, tachypnoea, or an irregular respiratory pattern. Moreover, levodopa can induce an oromandibular or laryngeal dystonia $[71,72]$ which can generate a worsening of respiratory disease by obstructing the upper airways. These respiratory disorders tend to resolve with the drug suspension, but in some cases levodopa withdrawal has been associated with a worsening of larynx dystonia, stridor, and chest muscular stiffness, which can be further worsened by panic crises induced by the reduced capacity of expanding the chest [73-75].

The mechanisms of levodopa-induced respiratory dyskinesia are not well understood; however, it has been hypothesized a hypersensivity due to a denervation of dopaminergic receptors mediated by exogenous dopamine in central chemoreceptors [76]. Dopamine is adopted both in central pontine and peripheral chemoreceptors. As hypoxia increases, endogenous dopamine synthesis and release from carotid receptor cells increase [77]. A reduced peripheral chemosensibility could, at least in part, justify the reduced response to hypoxaemia observed in PD [78]. This complication should be treated as the other levodopa-associated motor fluctuations and dyskinesias [79]. Some case-reports underlined that cab- 
ergoline, pergolide, bromocriptine, and ergot-derived drugs can be associated with lung and pleural fibrosis and with pleural effusions. Symptoms can be severe, being not observed in patients not assuming other dopamine agonist agents, as pramipexole or rotigotine [80-82]. Respiratory symptoms typically appear within 3 years from treatment start; however, some cases are described up to 11 years from the beginning of treatment [83]; these subjects develop a dyspnoea associated with an interstitial lung disease associated with pleural effusion or pleural thickening, with a restrictive spirometric pattern. Histopathology underlines lung and pleural fibrosis, with chronic inflammatory infiltrate [83]. The mechanism of disease is not well-understood, and some authors suggest that ergot agonists can activate the lung 5HT-2B receptors and stimulate fibroblasts, inducing cell growth, growth factors production, and extracellular matrix production [84].

Effect of Drugs Adopted in Respiratory Diseases in AD Inhaled anticholinergic drugs use has been associated with a greater risk of cognitive deterioration $[85,86]$, and among elderly patients, to more hospital admissions for delirium [87]. Inhaled steroids use has been associated with an increased risk of cognitive deterioration among female individuals [88]. Treatment for lung cancer has been associated with a deterioration of verbal and visuospatial abilities, and associated with anatomic alterations in limbic regions and in white and grey matter of the cortex [89].

\section{Effects of Drugs Used in Respiratory Diseases in PD}

and Parkinsonisms

Some studies underlined a positive effect of long-acting beta-2 agonists as salmeterol in reducing Parkinson and parkinsonisms symptoms in the animal model [90,
91], but there are no studies confirming a positive effect of this class of inhalator drugs used in COPD in this group of degenerative diseases. Inhaled anticholinergic drugs, as tiotropium or ipratropium bromide have a potential synergistic effect with antiparkinsonian drugs, as levodopa. This can increase the therapeutic effect of levodopa but also increase the collateral effects, as late dyskinesia. Ipratropium bromide, in inhaled formulation, has also been suggested as a potential treatment for sialorrhoea in patients affected by PD and parkinsonisms [92, 93].

\section{Conclusions}

As clinical complexity increases, mainly due to ageing of the population, different professionals must be aware of the common risk factors and of the potential interactions between chronic respiratory disorders and neurodegenerative diseases.

\section{Conflict of Interest Statement}

The authors have no conflicts of interest to declare.

\section{Funding Sources}

The authors did not receive any funding.

\section{Author Contributions}

L.F., G.V.: conceptualization, methodology, investigation (review) and writing (original draft); V.Z., N.T., L.N., C.N.: investigation (review), writing (review and editing) and data curation; A.S., G.M., M.S.: conceptualization, validation, supervision and writing (review and editing).

\section{References}

1 GBD 2013 Mortality and Causes of Death Collaborators. Global, regional, and national agesex specific all-cause and cause-specific mortality for 240 causes of death, 1990-2013: a systematic analysis for the global burden of disease study 2013. Lancet. 2014 Dec;385:117-71.

2 Durazzo TC, Mattsson N, Weiner MW. Smoking and increased Alzheimer's disease risk: a review of potential mechanisms. Alzheimers Dement. 2014 Jun;10(3 Suppl 1):S122-45.

3 Kivipelto M, Rovio S, Ngandu T, Kåreholt I, Eskelinen M, Winblad B, et al. Apolipoprotein E epsilon4 magnifies lifestyle risks for dementia: a population-based study. J Cell Mol Med. 2008 Dec;12:2762-71.
4 Barnes DE, Yaffe K. The projected effect of risk factor reduction on Alzheimer's disease prevalence. Lancet Neurol. 2011 Sep;10:819-28.

5 Ott A, Slooter AJ, Hofman A, van Harskamp F, Witteman JC, Van Broeckhoven C, et al. Smoking and risk of dementia and Alzheimer's disease in a population-based cohort study: the Rotterdam Study. Lancet. 1998 Jun [cited 2015 Dec 4];351:1840-3.

6 Tyas SL, White LR, Petrovitch H, Webster Ross G, Foley DJ, Heimovitz HK, et al. Mid-life smoking and late-life dementia: the HonoluluAsia aging study. Neurobiol Aging. 2003 JulAug [cited 2015 Dec 4];24:589-96.
7 Rusanen M, Rovio S, Ngandu T, Nissinen A, Tuomilehto J, Soininen H, et al. Midlife smoking, apolipoprotein $\mathrm{E}$ and risk of dementia and Alzheimer's disease: a population-based cardiovascular risk factors, aging and dementia study. Dement Geriatr Cogn Disord. 2010 Jan; 30:277-84.

8 Durazzo TC, Meyerhoff DJ, Nixon SJ. Chronic cigarette smoking: implications for neurocognition and brain neurobiology. Int $J$ Environ Res Public Health. 2010 Oct;7:3760-91.

9 Sharma A, Brody AL. In vivo brain imaging of human exposure to nicotine and tobacco. Handb Exp Pharmacol. 2009 Jan;(192):145-71.
Respiratory Diseases in Chronic

Neurologic Disorders
Med Princ Pract 2021;30:501-507

DOI: $10.1159 / 000518261$ 
10 Azizian A, Monterosso J, O’Neill J, London ED. Magnetic resonance imaging studies of cigarette smoking. Handb Exp Pharmacol. 2009 Jan;(192):113-43.

11 Grant I, Heaton RK, McSweeny AJ, Adams KM, Timms RM. Neuropsychologic findings in hypoxemic chronic obstructive pulmonary disease. Arch Intern Med. 1982 Aug [cited 2015 Dec 4];142:1470-6.

12 Schou L, Østergaard B, Rasmussen LS, RydahlHansen S, Phanareth K. Cognitive dysfunction in patients with chronic obstructive pulmonary disease: a systematic review. Respir Med. 2012 Aug;106:1071-81.

13 Antonelli-Incalzi R, Corsonello A, Pedone C, Trojano L, Acanfora D, Spada A, et al. Drawing impairment predicts mortality in severe COPD. Chest. 2006 Dec;130:1687-94.

14 Incalzi RA, Gemma A, Marra C, Muzzolon R, Capparella O, Carbonin P. Chronic obstructive pulmonary disease. An original model of cognitive decline. Am Rev Respir Dis. 1993 Aug;148: 418-24.

15 Hung WW, Wisnivesky JP, Siu AL, Ross JS. Cognitive decline among patients with chronic obstructive pulmonary disease. Am J Respir Crit Care Med. 2009;180:134-7.

16 Villeneuve S, Pepin V, Rahayel S, Bertrand JA, de Lorimier M, Rizk A, et al. Mild cognitive impairment in moderate to severe COPD. Chest. 2012 Dec;142(6):1516.

17 Rusanen M, Ngandu T, Laatikainen T, Tuomilehto J, Soininen H, Kivipelto M. Chronic obstructive pulmonary disease and asthma and the risk of mild cognitive impairment and dementia: a population based CAIDE study. Curr Alzheimer Res. 2013 Jun [cited 2015 Dec 4];10: 549-55.

18 Abrams B. Add Alzheimer's to the list of sleep apnea consequences. Med Hypotheses. 2005 Jan;65:1201-2.

19 Kadotani H, Kadotani T, Young T, Peppard PE Finn L, Colrain IM, et al. Association between apolipoprotein E epsilon4 and sleep-disordered breathing in adults. JAMA. 2001 Jun [cited 2015 Dec 4];285:2888-90.

20 Ancoli-Israel S, Palmer BW, Cooke JR, CoreyBloom J, Fiorentino L, Natarajan L, et al. Cognitive effects of treating obstructive sleep apnea in Alzheimer's disease: a randomized controlled study. J Am Geriatr Soc. 2008 Nov;56:2076-81.

21 Buratti L, Viticchi G, Falsetti L, Cagnetti C, Luzzi S, Bartolini M, et al. Vascular impairment in Alzheimer's disease: the role of obstructive sleep apnea. J Alzheimers Dis. 2014 Jan;38:44553.

22 Buratti L, Viticchi G, Baldinelli S, Falsetti L Luzzi S, Pulcini A, et al. Sleep apnea, cognitive profile, and vascular changes: an intriguing relationship. J Alzheimers Dis. 2017;60:1195.

23 Zhang F, Niu L, Li S, Le W. Pathological impacts of chronic hypoxia on Alzheimer's disease. ACS Chem Neurosci. 2019 Feb; 10:902-9.

24 Cooke JR, Ayalon L, Palmer BW, Loredo JS, Corey-Bloom J, Natarajan L, et al. Sustained use of CPAP slows deterioration of cognition, sleep, and mood in patients with Alzheimer's disease and obstructive sleep apnea: a preliminary study. J Clin Sleep Med. 2009 Aug [cited 2015 Nov 20];5:305-9.

25 Catalá-López F, Suárez-Pinilla M, Suárez-Pinilla P, Valderas JM, Gómez-Beneyto M, Martinez $S$, et al. Inverse and direct cancer comorbidity in people with central nervous system disorders: a meta-analysis of cancer incidence in 577,013 participants of 50 observational studies. Psychother Psychosom. 2014 Jan;83:89105.

26 Ou SM, Lee YJ, Hu YW, Liu CJ, Chen TJ, Fuh $\mathrm{JL}$, et al. Does Alzheimer's disease protect against cancers? A nationwide populationbased study. Neuroepidemiology. 2012 Dec;40: 42-9.

27 Sánchez-Valle J, Tejero H, Ibáñez K, Portero JL Krallinger M, Al-Shahrour F, et al. A molecular hypothesis to explain direct and inverse comorbidities between Alzheimer's disease, glioblastoma and lung cancer. Sci Rep. 2017;7: 4474.

28 Park MH, Yun HM, Hwang CJ, Park SI, Han SB, Hwang DY, et al. Presenilin mutation suppresses lung tumorigenesis via inhibition of peroxiredoxin 6 activity and expression. Theranostics. 2017;7:3624.

29 Greco A, Valle JS, Pancaldi V, Baudot A, Barillot E, Caselle M, et al. Molecular inverse comorbidity between Alzheimer's disease and lung cancer: new insights from matrix factorization. Int J Mol Sci. 2019 Jul;20(13):3114.

30 Kiyohara C, Kusuhara S. Cigarette smoking and Parkinson's disease: a meta-analysis. Fukuoka Igaku Zasshi. 2011 Aug;102(8):25465.

31 Hernán MA, Takkouche B, Caamaño-Isorna F, Gestal-Otero JJ. A meta-analysis of coffee drinking, cigarette smoking, and the risk of Parkinson's disease. Ann Neurol. 2002 Sep;52: 276-84.

32 Ritz B, Lee PC, Lassen CF, Arah OA. Parkinson disease and smoking revisited: ease of quitting is an early sign of the disease. Neurology. 2014 Oct; $83: 1396-402$.

33 Li CH, Chen WC, Liao WC, Tu CY, Lin CL, Sung FC, et al. The association between chronic obstructive pulmonary disease and Parkinson's disease: a nationwide population-based retrospective cohort study. QJM. 2015 Jan;108: $39-45$

34 Nóbrega AC, Rodrigues B, Melo A. Is silent aspiration a risk factor for respiratory infection in Parkinson's disease patients? Parkinsonism Relat Disord. 2008 Dec;14:646-8.

35 Regan J, Walshe M, Tobin WO. Immediate effects of thermal-tactile stimulation on timing of swallow in idiopathic Parkinson's disease. Dysphagia. 2010 Sep;25:207-15.

36 Kalf JG, de Swart BJM, Bloem BR, Munneke M. Prevalence of oropharyngeal dysphagia in Parkinson's disease: a meta-analysis. Park Relat Disord. 2012 May;18:311-5.

37 Cardasis JJ, MacMahon H, Husain AN. The spectrum of lung disease due to chronic occult aspiration. Ann Am Thorac Soc. 2014 Jul;11: 865-73.
38 Mukhopadhyay S, Katzenstein AL. Pulmonary disease due to aspiration of food and other particulate matter: a clinicopathologic study of 59 cases diagnosed on biopsy or resection specimens. Am J Surg Pathol. 2007 May;31:752-9.

39 Sabaté M, González I, Ruperez F, Rodríguez M. Obstructive and restrictive pulmonary dysfunctions in Parkinson's disease. J Neurol Sci. 1996;138:114-9.

40 Sabaté M, Rodríguez M, Méndez E, Enríquez E, González I. Obstructive and restrictive pulmonary dysfunction increases disability in Parkinson disease. Arch Phys Med Rehabil. 1996;77: 29-34.

41 Estenne M, Hubert M, de Troyer A, Vincken WG, Gauthier SG, Dollfuss RE, et al. Respiratory-muscle involvement in Parkinson's disease. N Engl J Med. 1984 Dec;311(23):1516-7.

42 Jankovic J. Camptocormia, head drop and other bent spine syndromes: heterogeneous etiology and pathogenesis of parkinsonian deformities. Mov Disord. 2010 Apr;25:527-8.

43 Sathyaprabha TN, Kapavarapu PK, Pall PK, Thennarasu K, Raju TR. Pulmonary functions in Parkinson's disease. Indian J Chest Dis Allied Sci. 2005 [cited 2020 Oct 6];47(4):251-7. Available from: https://www.researchgate.net/publication/7512303.

44 Saleem AF, Sapienza CM, Okun MS. Respiratory muscle strength training: treatment and response duration in a patient with early idiopathic Parkinson's disease. NeuroRehabilitation. 2005 Jan;20:323-33.

45 Stanley RK, Protas EJ, Jankovic J. Exercise performance in those having Parkinson's disease and healthy normals. Med Sci Sports Exerc. 1999;31:761-6.

46 Inzelberg R, Peleg N, Nisipeanu P, Magadle R, Carasso RL, Weiner P. Inspiratory muscle training and the perception of dyspnea in Parkinson's disease. Can J Neurol Sci. 2005;32: 213-7.

47 Wetter TC, Collado-Seidel V, Pollmächer T, Yassouridis A, Trenkwalder C. Sleep and periodic leg movement patterns in drug-free patients with Parkinson's disease and multiple system atrophy. Sleep. 2000 May;23:361-7.

48 Arnulf I, Konofal E, Merino-Andreu M, Houeto JL, Mesnage V, Welter ML, et al. Parkinson's disease and sleepiness: an integral part of $\mathrm{PD}$. Neurology. 2002 Apr;58:1019-24.

49 Maria B, Sophia S, Michalis M, Charalampos L, Andreas P, John ME, et al. Sleep breathing disorders in patients with idiopathic Parkinson's disease. Respir Med. 2003 Oct;97:1151-7.

50 Diederich NJ, Vaillant M, Leischen M, Mancuso G, Golinval S, Nati R, et al. Sleep apnea syndrome in Parkinson's disease. A case-control study in 49 patients. Mov Disord. 2005;20: 1413-8.

51 Dhawan V, Healy DG, Pal S, Chaudhuri KR. Sleep-related problems of Parkinson's disease. Age Ageing. 2006 May;35:220-8.

52 Valko PO, Hauser S, Sommerauer M, Werth E, Baumann CR. Observations on sleep-disordered breathing in idiopathic Parkinson's disease. PLoS One. 2014 Jun;9:e100828. 
53 Chaudhuri KR, Healy DG, Schapira AHV. Non-motor symptoms of Parkinson's disease: diagnosis and management. Lancet Neurol. 2006 Mar;5:235-45.

54 Bajaj A, Driver JA, Schernhammer ES. Parkinson's disease and cancer risk: a systematic review and meta-analysis. Cancer Causes Control. 2010 May;21:697-707.

55 Goldacre M. Differential risks of cancer types in people with Parkinson's disease: a national record-linkage study. Eur J Cancer. 2014 Sep;50: 2456-62.

56 Driver JA, Logroscino G, Buring JE, Gaziano JM, Kurth T. A prospective cohort study of cancer incidence following the diagnosis of Parkinson's disease. Cancer Epidemiol Biomarkers Prev. 2007 Jun;16:1260-5.

57 Litvan I, Mangone CA, McKee A, Verny M, Parsa A, Jellinger K, et al. Natural history of progressive supranuclear palsy (steele-richardson-olszewski syndrome) and clinical predictors of survival: a clinicopathological study. J Neurol Neurosurg Psychiatry. 1996;60:615-20.

58 Mehanna R, Jankovic J. Respiratory problems in neurologic movement disorders. Parkinsonism Relat Disord. 2010 Dec;16:628-38.

59 Köllensperger M, Geser F, Seppi K, StampferKountchev M, Sawires M, Scherfler C, et al. Red flags for multiple system atrophy. Mov Disord. 2008 Jun;23:1093-9.

60 Ghoroyeb I, Bioulac B, Tison F, Hirayama M, Sobue G, Fukatsu H, et al. Relationship between stridor and sleep apnoea syndrome: is it as simple as that? [11] (multiple letters). J Neurol Neurosurg Psychiatry. 2004 [cited 2020 Oct 6]; 75:512-3.

61 Isono S, Shiba K, Yamaguchi M, Tanaka A, Hattori T, Konno A, et al. Pathogenesis of laryngeal narrowing in patients with multiple system atrophy. J Physiol. 2001 Oct;536:23749.

62 Ghorayeb I, Bioulac B, Tison F. Sleep disorders in multiple system atrophy. J Neural Transm. 2005;112:1669-75.

63 Iranzo A, Santamaria J, Tolosa E. Continuous positive air pressure eliminates nocturnal stridor in multiple system atrophy. Barcelona Multiple System Atrophy Study Group. Lancet. 2000 Oct:356:1329-30.

64 Nonaka M, Imai T, Shintani T, Kawamata M, Chiba S, Matsumoto H. Non-invasive positive pressure ventilation for laryngeal contraction disorder during sleep in multiple system atrophy. J Neurol Sci. 2006 Aug;247:53-8.

65 Guo X, Waern M, Sjögren K, Lissner L, Bengtsson $\mathrm{C}$, Björkelund C, et al. Midlife respiratory function and incidence of Alzheimer's disease: a 29-year longitudinal study in women. Neurobiol Aging. 2007 Mar;28:343-50.

66 Guo X, Pantoni L, Simoni M, Gustafson D, Bengtsson C, Palmertz B, et al. Midlife respiratory function related to white matter lesions and lacunar infarcts in late life: the prospective population study of women in Gothenburg, Sweden. Stroke. 2006 Jul;37:1658-62.
67 Pathan SS, Gottesman RF, Mosley TH, Knopman DS, Sharrett AR, Alonso A. Association of lung function with cognitive decline and dementia: the atherosclerosis risk in communities (ARIC) study. Eur J Neurol. 2011 Jun;18:88898.

68 Bonner LT, Peskind ER. Pharmacologic treatments of dementia. Med Clin North Am. 2002 May [cited 2015 Dec 4];86:657-74

69 Taylor AM, Hoehns JD, Anderson DM, Tobert DG, Morand BR, Demers D. Fatal aspiration pneumonia during transition from donepezil to rivastigmine. Ann Pharmacother. 2002 Oct; 36:1550-3.

70 Moraes W, Poyares D, Sukys-Claudino L, Guilleminault C, Tufik S. Donepezil improves obstructive sleep apnea in Alzheimer disease: a double-blind, placebo-controlled study. Chest. 2008:133:677-83

71 Kato B, Yamada K, Horiuchi M, Hirayama T, Hasegawa Y. [Case of Parkinson's disease presenting with unique dyspneic attacks caused by oromandibular dystonia and sleep apnea syndrome]. Rinsho Shinkeigaku. 2007 Sep [cited 2020 Oct 6];47:577-80. Japanese.

72 Onoue H, Yukitake M, Kurohara K, Takasima H, Kuroda Y. [A case report of Parkinson's disease presenting with recurrent dyspneic attacks due to focal laryngeal dystonia]. Rinsho Shinkeigaku. 2003 Apr [cited 2020 Oct 6];43: 192-4. Japanese.

73 Hartman DE. Stridor during dystonia phases of Parkinson's disease. J Neurol Neurosurg Psychiatry. 1988;51:161.

74 Vázquez A, Jiménez-Jiménez FJ, García-Ruiz P, García-Urra D. "Panic attacks" in Parkinson's disease: a long-term complication of levodopatherapy. Acta Neurol Scand. 1993 Jan; 87:14-8.

75 Shill H, Stacy M. Respiratory complications of Parkinson's disease. Semin Respir Crit Care Med. 2002;23:261-5.

76 Rice JE, Antic R, Thompson PD. Disordered respiration as a levodopa-induced dyskinesia in Parkinson's disease. Mov Disord. 2002 May; 17: $524-7$.

77 Iturriaga R, Alcayaga J, Gonzalez C. Neurotransmitters in carotid body function: the case of dopamine. Adv Exp Med Biol. 2009;648: $137-43$.

78 Serebrovskaya T, Karaban I, Mankovskaya I, Bernardi L, Passino C, Appenzeller O. Hypoxic ventilatory responses and gas exchange in patients with Parkinson's disease. Respiration. 1998 Jan;65:28-33.

79 Jankovic J, Aguilar LG. Current approaches to the treatment of Parkinson's disease. Neuropsychiatr Dis Treat. 2008;4:743-57.

80 Belmonte Y, de Fabregues O, Marti M, Domingo C. Pleuropulmonary toxicity of another anti-Parkinson's drug: cabergoline. Open Respir Med J. 2009 Jun;3:90-3.

81 Guptha SH, Promnitz AD. Pleural effusion and thickening due to cabergoline use in a patient with Parkinson's disease. Eur J Intern Med. 2005;16:129-31.
82 Villavicencio C, Ramírez-Sarmiento A, Gayete A, Grau S, Orozco-Levi M. [Early pleuropulmonary toxicity associated with cabergoline, an antiparkinsonian drug]. Arch Bronconeumol. 2007 Jan;43:519-22. Spanish

83 Tintner R, Manian P, Gauthier P, Jankovic J. Pleuropulmonary fibrosis after long-term treatment with the dopamine agonist pergolide for Parkinson disease. Arch Neurol. 2005 Aug; 62:1290-5.

84 Hofmann C, Penner U, Dorow R, Pertz HH, Jähnichen S, Horowski R, et al. Lisuride, a dopamine receptor agonist with 5-HT2B receptor antagonist properties: absence of cardiac valvulopathy adverse drug reaction reports supports the concept of a crucial role for 5-HT2B receptor agonism in cardiac valvular fibrosis. Clin Neuropharmacol. 2006 Mar;29:80-6.

85 Gray SL, Anderson ML, Dublin S, Hanlon JT, Hubbard R, Walker R, et al. Cumulative use of strong anticholinergics and incident dementia: a prospective cohort study. JAMA Intern Med. 2015 Mar; 175:401-7.

86 Carrière I, Fourrier-Reglat A, Dartigues JF, Rouaud O, Pasquier F, Ritchie K, et al. Drugs with anticholinergic properties, cognitive decline, and dementia in an elderly general population: the 3-city study. Arch Intern Med. 2009 Jul;169:1317-24.

87 Kalisch Ellett LM, Pratt NL, Ramsay EN, Barratt JD, Roughead EE. Multiple anticholinergic medication use and risk of hospital admission for confusion or dementia. J Am Geriatr Soc. 2014 Oct;62:1916-22.

88 Ancelin ML, Carrière I, Helmer C, Rouaud O, Pasquier F, Berr C, et al. Steroid and nonsteroidal anti-inflammatory drugs, cognitive decline, and dementia. Neurobiol Aging. 2012 Sep;33: 2082-90.

89 Simó M, Root JC, Vaquero L, Ripollés P, Jové J, Ahles $\mathrm{T}$, et al. Cognitive and brain structura changes in a lung cancer population. J Thorac Oncol. 2015 Jan;10:38-45.

90 Qian L, Wu HM, Chen SH, Zhang D, Ali SF, Peterson L, et al. $\beta 2$-Adrenergic receptor activation prevents rodent dopaminergic neurotoxicity by inhibiting microglia via a novel signaling pathway. J Immunol. 2011 Apr;186(7): 4443-54.

91 Peterson L, Ismond KP, Chapman E, Flood P. Potential benefits of therapeutic use of $\beta 2$ adrenergic receptor agonists in neuroprotection and Parkinsonus disease. J Immunol Res. 2014;2014:103780.

92 Seppi K, Weintraub D, Coelho M, Perez-Lloret S, Fox SH, Katzenschlager R, et al. The movement disorder society evidence-based medicine review update: treatments for the non-motor symptoms of Parkinson's disease. Mov Disord. 2011 Oct;26 Suppl 3:S42-80.

93 Thomsen TR, Galpern WR, Asante A, Arenovich T, Fox SH. Ipratropium bromide spray as treatment for sialorrhea in Parkinson's disease. Mov Disord. 2007 Nov;22:2268-73. 